\title{
El rompecabezas tributario en la Constitución colombiana ${ }^{1}$
}

\section{Tax Puzzle in the Colombian Constitution}

\author{
Alejandro Delgado Perea ${ }^{2}$
}

\section{Resumen}

Las disposiciones constitucionales sobre asuntos tributarios están dispersas en varios capítulos de la Carta, lo cual dificulta la armónica interpretación de algunas de ellas. Por imprecisión en la redacción, las altas cortes, vía jurisprudencia, se han visto obligadas a clarificar la intención del constituyente en materia de poder tributario.

En la primera parte de este documento se hace un recuento de los artículos constitucionales que tratan asuntos de naturaleza tributaria, lo cual muestra la dimensión de la dispersión normativa, y se comenta sobre lo que, en nuestro sentir, son aciertos y yerros del constituyente al redactar preceptos en la materia. En la segunda parte, el artículo deja atrás las consideraciones semánticas o de técnica normativa, para concentrarse en un tema esencial, en la columna vertebral del rompecabezas tributario: el poder originador. Se analiza la intención del constituyente en esta materia, en particular en la reserva de ley, y se incluye un breve recuento de la línea jurisprudencial de la Corte Constitucional sobre las atribuciones de las entidades territoriales.

\begin{abstract}
The constitutional provisions on tax matters are scattered in various chapters of the Constitution, which hinders the harmonious interpretation of some of them. Due to imprecisions in the wording, the high courts, via case law, have been forced to define what intention had the Constituent Assembly when drafting taxation principles.

The first part of this document summaries the constitutional articles dealing with issues of tax nature, which shows regulatory dispersion regarding the subject. Some comments are made on what, in our opinion, are successes and mistakes of the Constituent when drafting tax rules. In the
\end{abstract}

\footnotetext{
${ }^{1}$ Recibido el 1 de agosto de 2016. Aprobado el 20 de septiembre de 2016.

${ }^{2}$ Magíster en Derecho con énfasis en Tributación, de la Universidad Externado de Colombia. Especialista en Finanzas, egresado del programa Presidentes de Empresa e Ingeniero de la Universidad de los Andes. Cursó el Industrial Finance Seminar en el Industrial Bank of Japan, Tokio. Coach profesional certificado y acreditado ACC por la International Coach Federation. Actualmente es Presidente y Socio Director de Consultoría en Finanzas de Globbal Consulting SAS, Bogotá, Colombia.Correo-e: adelgado@globbal.com. Para citar el artículo: Delgado,A. (2016). "El rompecabezas tributario en la Constitución colombiana", en Revista de Derecho Fiscal n ${ }^{\circ}$ 9, Bogotá: Universidad Externado de Colombia. pp. 93-109. DOI: http://dx.doi.org/10.18601/16926722.n9.07
} 
second part, the article leaves behind semantics or considerations on legislative technique, to focus on a key issue, the backbone of the tax puzzle: the originating taxing power. the intention of the Constituent Assembly in this matter, particularly in the legal reserve, and includes a brief account of the jurisprudential line of the Constitutional Court on the powers of local authorities are analyzed.

\section{Breve explicación sobre los tipos de tributos}

El concepto tributo es amplio, y, como veremos enseguida, la doctrina ha desagregado las especies tributarias, grosso modo, en impuestos, tasas y contribuciones (Domingues \& Checa González, 2013).

Al redactar la Constitución Política de 1991, el constituyente empleó, en forma imprecisa, diversos términos para referirse a los tributos, a tal punto que la Corte Constitucional tuvo que precisar que "[1] a expresión 'contribuciones fiscales' ha de entenderse en un sentido lato, como sinónimo del concepto genérico de tributo, fuente de los denominados ingresos tributarios" (Sentencia C-134, 2009).

La diferencia entre los vocablos tributo, impuesto, contribución, contribución parafiscal, tasa y sobretasa, utilizados en la Carta Política, puede ser explicada, en una primera aproximación, directamente del Diccionario de la Lengua Española, en las acepciones relacionadas con el Derecho:

Tributo. [...] 4. Obligación dineraria establecida por la ley, cuyo importe se destina al sostenimiento de las cargas públicas.
Impuesto. [...] 2. Tributo que se exige en función de la capacidad económica de los obligados a su pago. directo. Impuesto que grava las fuentes de capacidad económica, como la renta y el patrimonio. [...] indirecto. Impuesto que grava el consumo o gasto.

Contribución. [...] 2. Cuota o cantidad que se paga para algún fin, y principalmente la que se impone para las cargas del Estado. [...] directa. Contribución que pesa sobre personas, bienes o usos determinados. $\sim$ especial. Tributo que se exige a quien se beneficia de la realización de obras públicas o del establecimiento de servicios públicos. [...] indirecta. Contribución que grava determinados actos de producción, comercio o consumo.

Tasa. [...] 3. Tributo que se impone al disfrute de ciertos servicios o al ejercicio de ciertas actividades

Sobretasa. Recargo sobre la tasa ordinaria (Real Academia Española, 2014).

Trabajos como el publicado por el Centro Interamericano de Administraciones Tributarias (Pecho-Trigueros, 2010) definen los términos tributarios en forma más precisa y técnica, con base en el Modelo de Código Tributario de esta organización (CIAT; GIZ; BID, 2015), y coincide en esencia con las acepciones del diccionario.

Los problemas de imprecisión en el uso de los vocablos técnico-tributarios no son una banalidad. De hecho, el primer acápite del referido trabajo de Pecho-Trigueros se titula "Problemas terminológicos": 
El art. 2 del Modelo de Código Tributario del CIAT (CIAT, 2006) ${ }^{3}$-el Modelo de aquí en adelante- define al concepto tributo, como la prestación en dinero que el Estado exige, mediante el ejercicio de su poder de imperio, con el objeto de obtener recursos para financiar el gasto público $y$, en su caso, para el cumplimiento de otros fines de interés general.

El art. 3 del Modelo define a la especie impuesto como el tributo cuya obligación tiene como hecho generador y como fundamento jurídico una situación independiente de toda actividad estatal relativa al contribuyente que pone de manifiesto una determinada capacidad contributiva del mismo. Dicho de otra forma, el pago del impuesto no origina por parte del Estado una contraprestación directa en favor del contribuyente.

El art. 4 del Modelo define a la especie tasa como el tributo cuya obligación tiene como hecho generador la prestación efectiva o potencial de un servicio en régimen de derecho público, el mismo que está individualizado en el contribuyente. Una característica fundamental es que la demanda del servicio es obligada, i.e. deriva de una ley, lo cual introduce en la tasa un elemento coactivo que la aproxima al impuesto pero la distancia del precio público. La magnitud de la tasa debe reflejar únicamente el costo del servicio.

El art. 5 del Modelo define a la especie contribución especial como el tributo que tiene como hecho generador los beneficios especiales derivados de la realización de obras públicas o el establecimiento de servicios públicos. La más relevante es la llamada contribución de mejora. (...) Si bien no existe una demanda individual, el ámbito de los beneficiados con la actividad pública es identificable, por lo que su costo puede ser distribuido correctamente. Asimismo, su producto no debe tener un destino ajeno a la financiación de las obras o las actividades que constituyen el presupuesto de la obligación.

Finalmente, a diferencia de los tributos, las contribuciones parafiscales son exacciones aplicadas a los usuarios por ciertos organismos públicos o semipúblicos, para asegurar su financiamiento. Generalmente, estas entidades gozan de personería jurídica y patrimonio propio, son autónomas en su funcionamiento, gestionan las prestaciones de servicios y la cobranza de las referidas exacciones. Las más relevantes de todas son las contribuciones sociales destinadas a financiar la seguridad social (destacados en el original) (Pecho-Trigueros, 2010, págs. 3-4) ${ }^{4}$.

Precisadas las diferencias terminológicas de los distintos tipos de tributos, podemos pasar a hacer una síntesis de los artículos superiores que hacen referencia a materias tributarias, y comentar hasta dónde su uso es acertado o impreciso. 


\section{La dispersión normativa en la Constitución}

El constituyente de 1991 no asignó un capítulo a la materia tributaria. Por el contrario, el espectro constitucional en esta materia está contenido en varios artículos de la Carta Política (C.P.) cobijados por capítulos y títulos que versan sobre tópicos disímiles. El tema no es un asunto menor o de simple forma, ya que por cuenta de ello la lectura e interpretación constitucional $-\mathrm{y}$ por consiguiente la aplicación- de las normas Superiores que regulan el sistema tributario resulta compleja e incierta, lo que ha sido fuente de un buen número de demandas de inexequibilidad de leyes, ordenanzas y acuerdos y, por ende, ha obligado a la Corte Constitucional y al Consejo de Estado a pronunciarse para, vía jurisprudencia, dar una interpretación armónica y coherente a lo que podemos llamar el sistema tributario constitucional.

La terminología usada en la Constitución tampoco es consistente ni del todo coherente: se hace referencia en forma imprecisa a tributos, contribuciones, impuestos y tasas.

Empecemos por hacer un recuento de las normas contenidas en la C.P. que tocan con tributos (se incluye el título y capítulo en los que está incluido cada artículo). En los comentarios se ha tenido el cuidado de mantener las palabras esenciales del artículo -tales como tributo, contribución y tasa- para fines de referencia y del análisis que más adelante se hará. En algunos casos, incluso, se consideró conveniente transcribir literalmente la norma.
TÍTULO II. DE LOS DERECHOS, LAS GARANTÍAS

Y LOS DEBERES

\section{CAPÍTULO 1. DE LOS DERECHOS FUNDAMENTALES}

El inciso 4 del art. 15 contempla una excepción al derecho fundamental a la intimidad, cuando determina que para efectos tributarios podrá exigirse la presentación de libros de contabilidad y demás documentos privados, en los términos que señale la ley.

\section{CAPÍTULO 5. DE LOS DEBERES Y OBLIGACIONES}

El art. 95 -único de este capítulo-, en el num. 9, establece la obligación que tiene toda persona de "contribuir al financiamiento de los gastos e inversiones del Estado dentro de conceptos de justicia y equidad".

\section{TÍTULO V. DE LA ORGANIZACIÓN DEL ESTADO}

\section{CAPÍTULO 2. DE LA FUNCIÓN PÚBLICA}

El art. 131 establece que compete a la ley la reglamentación del servicio público que prestan los notarios y registradores, y en particular lo relativo a los aportes como tributación especial de las notarías, con destino a la administración de justicia.

TÍTULOVI.DELARAMALEGISLATIVA

\section{CAPÍTULO 3. DE LAS LEYES}

El art. 150 dispone que le corresponde al Congreso hacer las leyes, y por medio de 
ellas ejerce las funciones de "11. Establecer las rentas nacionales y fijar los gastos de la administración. 12. Establecer contribuciones fiscales y, excepcionalmente, contribuciones parafiscales en los casos y bajo las condiciones que establezca la ley".

El numeral 10 del mismo artículo le prohíbe al Congreso conceder facultades al Presidente de la República para decretar impuestos.

El art. 154 limita las facultades de originación de ciertas leyes tributarias, cuando establece que "sólo podrán ser dictadas o reformadas por iniciativa del Gobierno las leyes [...] que ordenen participaciones en las rentas nacionales o transferencias de las mismas; [...] y las que decreten exenciones de impuestos, contribuciones o tasas nacionales".

De igual manera precisa el mecanismo formal de los proyectos de ley relativos a los tributos, al imponer que su trámite se debe iniciar en la Cámara de Representantes.

El art. 170, en su inciso 3, exceptúa la utilización del mecanismo de referendo para la derogatoria, entre otras, de leyes referentes a materias tributarias.

\section{TÍTULO VII. DE LA RAMA EJECUTIVA CAPÍTULO 1. DEL PRESIDENTE DE LA REPÚBLICA}

Una de las funciones del Presidente de la República es, de acuerdo con el num. 20 del Art. 189, “[v]elar por la estricta recaudación y administración de las rentas y caudales públicos y decretar su inversión de acuerdo con las leyes".

\section{TÍTULO VII. DE LA RAMA EJECUTIVA}

\section{CAPÍTULO 6. DE LOS ESTADOS DE EXCEPCIÓN}

El art. 215 faculta al Presidente para que, con la firma de todos los ministros, declare el Estado de Emergencia -que puede regir por períodos hasta de treinta días en cada caso, sin exceder de noventa días en el año calendario-. Bajo estas circunstancias excepcionales, puede expedir decretos transitorios con fuerza de ley para "establecer nuevos tributos o modificar los existentes. En estos últimos casos, las medidas dejarán de regir al término de la siguiente vigencia fiscal, salvo que el Congreso, durante el año siguiente, les otorgue carácter permanente".

\section{TÍTULO XI. DE LA ORGANIZACIÓN TERRITORIAL}

\section{CAPÍTULO 1. DE LAS DISPOSICIONES GENERALES}

En el art. 287 el constituyente prescribió la autonomía de las entidades territoriales para la gestión de sus intereses, dentro de los límites de la Constitución y la ley, en virtud de la cual tienen el derecho de "3. Administrar los recursos y establecer los tributos necesarios para el cumplimiento de sus funciones".

El art. 294 prohíbe que la ley conceda exenciones o tratamientos preferenciales en relación con los tributos de propiedad de las entidades territoriales, o imponer recargos sobre sus impuestos, salvo lo dispuesto en el artículo 317. 
CAPÍTULO 2. DEL RÉGIMEN DEPARTAMENTAL

El art. 300.4 dicta que les corresponde a las Asambleas Departamentales decretar, de conformidad con la Ley, los tributos y contribuciones necesarios para el cumplimiento de las funciones departamentales.

El num. 11 del art. 305 asigna al gobernador la responsabilidad de la "exacta recaudación" de las rentas departamentales, incluyendo las transferencias de la Nación.

\section{CAPÍTULO 3. DEL RÉGIMEN MUNICIPAL}

El art. 313.4 dicta que corresponde a los concejos municipales "votar de conformidad con la Constitución y la ley los tributos y los gastos locales".

El art. 317 reza: "Solo los municipios podrán gravar la propiedad inmueble. Lo anterior no obsta para que otras entidades impongan contribución de valorización". Y más adelante precisa la destinación parcial de estos recursos al decretar que "La ley destinará un porcentaje de estos tributos, que no podrá exceder del promedio de las sobretasas existentes, a las entidades encargadas del manejo y conservación del ambiente y de los recursos naturales renovables, de acuerdo con los planes de desarrollo de los municipios del área de su jurisdicción".

En las funciones del alcalde (art. 315), a diferencia de lo previsto en el caso del Presidente y los gobernadores, no está explícita la recaudación de las rentas. En cualquier caso, el num. 1 le ordena hacer cumplir los acuerdos (entre los que están aquellos que establezcan tributos] y el num. 3 le asigna la dirección de la "acción administrativa" del municipio [o distrito].

\section{TÍTULO XII. DEL RÉGIMEN ECONÓMICO Y DE LA HACIENDA PÚBLICA}

\section{CAPÍTULO 1. DE LAS DISPOSICIONES GENERALES}

El art. 338 dicta sobre la potestad tributaria y los elementos del tributo, cuando establece:

En tiempo de paz, solamente el Congreso, las asambleas departamentales y los concejos distritales y municipales podrán imponer contribuciones fiscales o parafiscales. La ley, las ordenanzas y los acuerdos deben fijar, directamente, los sujetos activos y pasivos, los hechos y las bases gravables, y las tarifas de los impuestos.

La ley, las ordenanzas y los acuerdos pueden permitir que las autoridades fijen la tarifa de las tasas y contribuciones que cobren a los contribuyentes, como recuperación de los costos de los servicios que les presten o participación en los beneficios que les proporcionen; pero el sistema y el método para definir tales costos y beneficios, y la forma de hacer su reparto, deben ser fijados por la ley, las ordenanzas o los acuerdos.

Las leyes, ordenanzas o acuerdos que regulen contribuciones en las que la base sea el resultado de hechos ocurridos durante un período determinado, no pueden aplicarse sino a partir del período que comience des- 
pués de iniciar la vigencia de la respectiva ley, ordenanza o acuerdo.

\section{CAPÍTULO 3. DEL PRESUPUESTO}

El art. 345 prescribe que en tiempo de paz no se podrá percibir contribución o impuesto que no figure en el presupuesto de rentas.

\section{CAPÍTULO 4.DELADISTRIBUCIÓN DE RECURSOS Y DE LAS COMPETENCIAS}

El art. 359 dispone que no habrá rentas nacionales de destinación específica, salvo las participaciones previstas en la Constitución en favor de los territorios, las destinadas para inversión social y las que, "con base en leyes anteriores, la Nación asigna a entidades de previsión social y a las antiguas intendencias y comisarías".

En el art. 362 el constituyente señaló que los bienes y rentas de las entidades territoriales son de su propiedad exclusiva, y tienen las mismas garantías que la propiedad y renta de los particulares. Los impuestos territoriales no podrán ser trasladados a la Nación, salvo temporalmente en caso de guerra exterior.

El art. 363 fija los principios en los que se funda el sistema tributario, a saber: equidad, eficiencia y progresividad. Y en párrafo aparte prohíbe la aplicación retroactiva de las leyes tributarias.

\section{DISPOSICIONES TRANSITORIAS}

\section{CAPÍTULO 7}

El art. Transitorio 43 estableció facultades especiales al Congreso para financiar las instituciones creadas por la nueva Constitución. Si el Congreso no actúa y el ejecutivo se esfuerza pero no logra hacer ahorros suficientes para sufragar los gastos adicionales, se faculta al Gobierno Nacional para, por una sola vez, realizar dichos ajustes ${ }^{5}$.

El recuento precedente muestra que, a lo largo de Constitución, el sistema normativo tributario está diseminado en títulos y capítulos que regulan temas diversos. Esta dispersión es por sí misma inconveniente $\mathrm{y}$, a nuestro juicio, antitécnica, y ha sido uno de los motivos de que, a lo largo de los 25 años de vigencia de la Constitución, la responsabilidad de armonizar el sistema haya recaído en la ley, que es el instrumento por excelencia para desarrollar los principios constitucionales. Pero también la tarea les ha correspondido a la Corte y, en menor medida, al Consejo de Estado, vía sentencias que no siempre, valga decirlo, han mantenido la misma línea jurisprudencial.

\footnotetext{
${ }^{5}$ La única norma que se expidió con base en esta disposición fue el art. 46 de la Ley 6 de 1992: "Contribución para la descentralización. Establécese la contribución para la descentralización, que se liquidará por Ecopetrol, a la tarifa del dieciocho por ciento (18\%) sobre la diferencia entre el precio final de venta al público de la gasolina y el monto de dicho precio vigente a la fecha de expedición de la presente ley.

(...)

PARÁGRAFO $2^{\circ}$. En desarrollo del artículo transitorio 43 de la Constitución Política, la contribución para la descentralización se destinará en forma exclusiva a la Nación para cubrir parcialmente las transferencias a los municipios".
} 
La ausencia en la C.P. de una unidad temática en asuntos tributarios, aunado a las imprecisiones en los términos tributarios usados en la Carta -asunto que se abordará en el siguiente numeral- es, por una parte, fuente de ambivalencias e inconsistencias que dejan espacios notables de incertidumbre jurídica y, por la otra, da lugar a discusiones sobre la constitucionalidad de leyes, ordenanzas y acuerdos. Con ello, sin duda, sobreviene inseguridad jurídica en una materia de suma importancia para la consolidación de principios, deberes y derechos esenciales previstos en la misma Carta, tales como el orden económico y social justo, la solidaridad y la prosperidad.

\section{Las inconsistencias y los aciertos terminológicos en las normas tributarias constitucionales}

El constituyente debe utilizar terminología precisa en la redacción de las disposiciones constitucionales, es decir, le corresponde distinguir con diferentes vocablos cuando sea menester hacerlo y dictar normas coherentes con esos términos, para así favorecer la seguridad jurídica, facilitarle al legislador su tarea de desarrollar los principios normativos, y allanarle el camino al intérprete constitucional para fijar jurisprudencia estable. Esta premisa es de particular aplicación en materia tributaria, debido al pulso permanente que existe entre administración y administrados (o, mejor, entre sujetos activos y pasivos de los tributos), y al impacto negativo que la incertidumbre jurídica tributaria genera en el desarrollo y ejercicio ar- mónico y confiable de los derechos sociales y económicos.

La terminología tributaria en nuestra Constitución no es consistente ni consonante con la teoría impositiva ni con los vocablos técnicos jurídicos aceptados por expertos en la materia. El constituyente hizo referencias desatinadas sobre tributos, impuestos, contribuciones (fiscales y para fiscales), tasas y sobretasas ${ }^{6}$, y con ello restó confiabilidad y armonía al sistema impositivo superior.

Para demostrar las imprecisiones en que se incurrió en la redacción de algunas disposiciones tributarias de la Carta, basta hacer un repaso de ellas: el art. 150 prescribe sobre contribuciones fiscales y contribuciones parafiscales, como si se tratara de conceptos universalmente comprendidos, y más adelante prohíbe que se le conceda al Presidente la facultad de decretar impuestos, cuando en realidad se quiso decir tributos; el art. 300 hace referencia a tributos y contribuciones, como conceptos distintos e independientes, y sin que sea claro el propósito de tal diferenciación; el art. 317 hace referencia a las sobretasas existentes cuando está hablando de impuestos sobre la propiedad inmueble y contribuciones especiales; el art. 362 trata de la garantía que tienen las rentas tributarias de las entidades territoriales (EE. TT.) y, al mismo tiempo, decreta acerca de la protección constitucional de los impuestos departamentales y municipales, como si rentas tributarias e impuestos fueran un mismo concepto; el art. 338 comienza hablando de las contribuciones fiscales o parafiscales, y

${ }^{6}$ La palabra tarifa fue correctamente utilizada en el texto constitucional, al referirla en forma precisa, según el caso, a la contraprestación por los servicios públicos, materia aduanera y a uno de los elementos definitorios de los tributos. 
atribuye luego a la ley, las ordenanzas y los acuerdos la potestad y obligación de fijar los elementos de los impuestos.

En otros artículos, por el contrario, el constituyente es consistente y ajustado a la teoría impositiva, al diferenciar los conceptos y vocablos: en los artículos 15, 131, $170,215,313,317$ y 363 habla en forma general y correcta de tributos; en el artículo 95.9 utiliza con acierto y en forma amplia el verbo contribuir como una obligación de todo ciudadano; en el artículo 154 diferencia bien impuestos, contribuciones y tasas; en el art. 294 diferencia en forma precisa -aunque cabe preguntarse si lo hizo deliberadamente-cuando prohíbe a la ley decretar exenciones sobre los tributos de propiedad de las EE. TT., así como imponer recargos sobre sus impuestos; en el 317 habla puntualmente de contribución de valorización; en el art. 345 distingue bien contribuciones de impuestos; y, finalmente, en el art. 338, en su inciso segundo, separa en forma precisa las contribuciones y las tasas, de los impuestos, aunque estas contribuciones -sin adjetivo-parecen ser diferentes de aquellas contribuciones -fiscales y parafiscales-que menciona en el inciso primero.

Si el constituyente hubiera dedicado a la materia tributaria un capítulo especial dentro del título que versa sobre hacienda pública, o al menos si hubiera conservado armonía temática y semántica, el país contaría con un sistema constitucional tributario consistente y con mayor certidumbre jurídica. Es claro que la concordancia entre normas hubiera obligado a tocar el tema tributario en varios acápites y disposiciones, pero habría sido mucho más fácil asegurar que la ley desarrollara los principios constitucionales y que el vigilante de la Constitución los preservara con jurisprudencia menos mutable.

Uno de los aspectos en los que la ausencia del capítulo sobre tributos termina por dejar un delicado vacío conceptual es el de la potestad tributaria, en particular la reserva de ley, uno de los ejes cardinales del sistema tributario, tema que será tratado en el siguiente numeral.

\section{La potestad tributaria y la reserva de ley}

Algunos autores distinguen el poder tributario, definido como la facultad de crear tributos, de la potestad tributaria, consistente esta última en la atribución administrativa de conseguir la aplicación de las normas tributarias y la materialización del tributo, usando para ello competencias tales como el recaudo y la fiscalización (Insignares Gómez \& Sánchez Peña, 2010). No obstante, la Corte hace referencia en la generalidad de sus sentencias a la potestad tributaria como el poder constitucional e indelegable de crear, establecer o regular tributos ${ }^{7}$. Así las cosas, en este acápite se habla indistintamente, como se ha hecho a lo largo del texto, de poder tributario o potestad tributaria, que es una atribución constitucional otorgada al Congreso, las asambleas y los concejos, claramente diferenciada de la facultad de gestión tributaria que la ley concede a la administración.

El artículo 338 otorga la potestad impositiva, sin distinción alguna, al Congreso, a

\footnotetext{
${ }^{7}$ Ver, por ejemplo, las sentencias C-987 de 1999, C-155 de 2003, C-134 de 2009, C-615 de 2013 y C-260 de 2015.

Revista de Derecho Fiscal n. ${ }^{\circ} 9 \cdot$ julio-diciembre de 2016 • pp. 93-109
} 
las asambleas departamentales y a los concejos municipales $^{8}$. El artículo 287 concede autonomía a las EE. TT. para la "gestión de sus intereses", dentro de los límites de la Constitución y la ley. En desarrollo de esta facultad, el numeral 3 les permite "administrar los recursos y establecer los tributos necesarios para el cumplimiento de sus funciones" (destacado fuera del original).

El constituyente prohibió a las asambleas departamentales establecer tributos ex novo, cuando prescribió que los "tributos y contribuciones" que ellas decreten deben estar conformes con la ley (artículo 300.4 ${ }^{[9]}$ ). No así -al menos no en forma tan clara- en el caso de los concejos municipales o distritales, toda vez que el artículo 313.4 permite que los concejos voten los tributos locales "de conformidad con la Constitución y la ley”. Y ya vimos que los artículos constitucionales 287.3 y 338 les dan facultades a los concejos para establecer o imponer tributos.

La diferencia expresa en la forma como se redactaron las atribuciones tributarias de las asambleas y los concejos no ha sido materia tratada por la Corte Constitucional. Esta corporación ha sido consistente en defender la reserva de ley para la originación de los tributos, bajo argumentos de lectura sistemática de las normas constitucionales, en particular la condición del Estado como República unitaria y, como veremos más adelante, postulados de coherencia, armonía, conveniencia y seguridad jurídica. En el sentir de la Corte, estos elementos del orden constitucional serían fracturados si se les permite a las EE. TT. crear tributos a su discreción.

La Corte (Sentencia C-891, 2012) se refiere a la preocupación de la Asamblea Nacional Constituyente de 1991 en relación con la descentralización. La descentralización implica, junto con la distribución de funciones, la asignación de los recursos necesarios para hacer posible su cumplimiento. Y preocupaba al constituyente que "las nuevas funciones llegaron con presteza mas no así los recursos necesarios para poderlas cumplir" (ibídem, págs. 25-26). La Corte afirma que "la verdadera descentralización es la que respalda financieramente las competencias que centro transfiere a la periferia” (ibídem, pág. 26).

Los fragmentos citados, que el magistrado ponente tomó de la Gaceta Constitucional 53 (Asamblea Nacional Constituyente, $1991)^{10}$, nos lleva a preguntarnos hasta dónde la intención real del constituyente fue permitir que los municipios tuvieran una facultad equiparable a la del Congreso en materia tributaria. Insistimos en que llama la atención la diferencia en la sujeción expresa de los atributos de las asambleas a los mandatos de la ley, mientras que para los concejos se extiende su potestad tributaria a lo permitido por la Constitución, como por ejemplo lo plasmado en el artículo 338 y otros concordantes.

Así las cosas, no es cristalina la intención del constituyente. Y podría entenderse que quiso dotar a las entidades territoriales de una fuerte autonomía en materia tributaria (Upegui Mejía, 2009).

\footnotetext{
${ }^{8}$ Se debe entender que la expresión "municipales" se extiende a "distritales".

${ }^{9} \mathrm{El}$ art. 300 fue modificado por el artículo 2 del Acto Legislativo 01 de 1996. El numeral 4 no fue cambiado.

${ }^{10}$ El texto completo de La Gaceta Constitucional 53 puede consultarse en https://www.yumpu. com/es/document/view/14373187/gaceta-constitucional-numero-53-el-abedul.
} 
Rodríguez Gutiérrez (2005) propone una interpretación del condicionamiento legal de la potestad tributaria territorial, según la cual las asambleas y los concejos, al dictar tributos, no estarían sometidos a una ley específica originadora del tributo, sino a las facultades que se derivarían de una ley orgánica de asignación de competencias a los territorios, según lo dispone el artículo 151 de la Carta ${ }^{11}$. En el mismo sentido se expresan Insignares y Sánchez cuando afirman que una ley orgánica permitiría establecer "una clara distribución de las competencias normativas entre la Nación y los entes, y [...] armonizar el principio de legalidad con la autonomía fiscal de que gozan estas entidades" (Insignares Gómez y Sánchez Peña, 2010, pág. 79). No obstante, la única ley orgánica que ha dictado el Congreso para desarrollar las competencias territoriales, la Ley 1454 de 2006, no contempló en su articulado asuntos tributarios.

Al margen de cualquier consideración, la Corte ha limitado al arbitrio de la ley, en forma clara, consistente y reiterada, la creación de los tributos, como se concluye de la lectura de todas sus sentencias en materia de potestad tributaria. La C-891 de 2012 (que recoge lo dicho en varias sentencias, entre ellas las C-004 de 1993, C-209 de 1993, C-228 de 1993, C-084 de 1995, C-537 de 1995, C-220 de 1996, C-390 de 1996, C-583 de 1996, C-413 de 1996, C-740 de 1999, C-987 de 1999, C-597 de 2000, C-1097 de 2001, C-227 de 2002, C-504 de 2002, C-155 de 2003, C-525 de 2003 y C-1043 de 2003) resume siete características propias del principio de legalidad ${ }^{12}$ : (i) es una expresión del principio de representación popular $^{13}$; (ii) materializa el principio que dicta que toda obligación fiscal debe ser fijado por ley previa y expresa ${ }^{14}$; (iii) da seguridad jurídica a los contribuyentes y garantiza el debido proceso $^{15}$; (iv) promueve una política fiscal coherente en el país, como República Unitaria ${ }^{16}$; (v) aplica a todo tipo de tributo. En los impuestos nacionales la ley debe definir todos su elementos ${ }^{17}$, pero

\footnotetext{
${ }^{11}$ Constitución Política. Artículo 151. "El Congreso expedirá leyes orgánicas a las cuales estará sujeto el ejercicio de la actividad legislativa. Por medio de ellas se establecerán [...], las normas [...] relativas a la asignación de competencias normativas a las entidades territoriales. Las leyes orgánicas requerirán, para su aprobación, la mayoría absoluta de los votos de los miembros de una y otra Cámara".

${ }^{12}$ Sentencias de la Corte Constitucional C-155 de 2003, M.P. Eduardo Montealegre Lynett, y C-525 de 2003, M.P. Manuel José Cepeda Espinosa.

${ }^{13}$ Sentencia de la Corte Constitucional C-227 de 2002, M.P. Jaime Córdoba Triviño. Ver también las Sentencias de la Corte Constitucional C-004-93, M.P. Ciro Angarita Barón; C-084 de 1995; C-413 de 1996, M.P. José Gregorio Hernández Galindo; C-987 de 1999; C-1097 de 2001; C-504 de 2002, M.P. Jaime Araújo Rentería, y C-1043 de 2003, M.P. Jaime Córdoba Triviño.

${ }^{14}$ Sentencias de la Corte Constitucional C-228 de 1993, M.P. Vladimiro Naranjo Mesa; C-413 de 1996, M.P. José Gregorio Hernández Galindo; C-987 de 1999, M.P. Alejandro Martínez Caballero; C-1097 de 2001; C-227 de 2002, M.P. Jaime Córdoba Triviño; C-504 de 2002, M.P. Jaime Araújo Rentería; y C-1043 de 2003, M.P. Jaime Córdoba Triviño.

${ }^{15}$ Sentencias de la Corte Constitucional C-597 de 2000, M.P. Álvaro Tafur Galvis, y C-1043 de 2003, M.P. Jaime Córdoba Triviño.

${ }^{16}$ Cfr. Sentencias de la Corte Constitucional C-413 de 1996, M.P. José Gregorio Hernández Galindo; C-1097 de 2001, M.P. Jaime Araújo Rentería; C-504 de 2002, M.P. Jaime Araújo Rentería, y C-1043 de 2003, M.P. Jaime Córdoba Triviño.

${ }^{17}$ Cfr. Sentencias de la Corte Constitucional C-004 de 1993, M.P. Eduardo Montealegre Lynett; C-084 de 1995, M.P. Alejandro Martínez Caballero; C-390 de 1996, M.P. José Gregorio Hernández Galindo; C-1097 de 2001, M.P. Jaime Araújo Rentería, y C-227 de 2002, M.P. Jaime Córdoba Triviño.
} 
en los territoriales concurre la competencia de las asambleas departamentales o de los concejos municipales, según sea el caso $^{18}$; (vi) junto con el legislador, las asambleas y los concejos están facultados para fijar los elementos constitutivos del tributo ${ }^{19}$, y (vii) es posible autorizar a las autoridades administrativas la fijación de las tarifas de las tasas y contribuciones que cobren a los contribuyentes, pero el sistema y el método para definir los costos, beneficios y la forma de hacer su reparto deben ser fijados por ley, ordenanzas o acuerdos ${ }^{20}$ (Sentencia C-891, 2012, págs. 19-20).

La Corte ha sido consistente en reservar a la ley la facultad de originación tributaria, pero, por el contrario, la jurisprudencia sobre el alcance de la potestad tributaria del Congreso y de las corporaciones colegiadas territoriales ha sido volátil durante la vigencia de la Constitución. En efecto, la Corte ha oscilado en su posición sobre el reparto de la potestad tributaria: en algunas sentencias, la Corte plantea la reserva de ley sin límites en su alcance, aunque deja en cabeza de las corporaciones territoriales una potestad residual, esto es, fijar los elementos del tributo que la ley no estableció ${ }^{21}$. En otras, interpreta que las facultades tributarias que el constituyente dio a las EE. TT. son inalienables y, a partir de ello, limita los alcances del Congreso al crear tributos de orden territorial y reconoce la competencia propia de las asambleas departamentales o los concejos municipales o distritales para fijar los elementos esenciales de los tributos, a fin de no vaciar la autonomía territorial ${ }^{22}$ :

(...) si el legislador, como puede hacerlo (artículos 295, 300-4 y 313-4), decide regular o establecer normas generales sobre tributos del orden departamental, municipal o distrital, no se le puede exigir, $n i$ debe permitírsele, que en la ley respectiva incluya directamente todos los componentes del tributo (...) -como sí está obligado a hacerlo tratándose de tributos nacionales-, pues su función no es, ni puede ser, según las reglas de la descentralización y la autonomía de las entidades territoriales, la de sustituir a los órganos de éstas en el ejercicio de la competencia que les ha sido asignada por la Constitución (Sentencia C-891, 2012) (destacado fuera del original).

Algunas sentencias afirman que basta con que la ley cree el tributo para que los entes territoriales puedan decretarlo y fijar todos sus elementos constitutivos ${ }^{23}$, mientras que en otras la Corte permitió que la ley agote todos los elementos del tributo -con lo cual la única facultad que le queda a la entidad territorial es decidir si lo adopta-o, en forma alternativa, la ley se limite a autorizarlo y a fijar sus aspectos básicos ${ }^{24}$, dejando así a los

\footnotetext{
${ }^{18}$ Sentencia de la Corte Constitucional C-227 de 2002.

${ }^{19}$ Sentencia de la Corte Constitucional C-740 de 1999, M.P. Álvaro Tafur Galvis. En relación con el principio de legalidad de los impuestos, pueden consultarse, igualmente, las sentencias C-209 de 1993, M.P. Alejandro Martínez Caballero; C-537 de 1995, Hernando Herrera Vergara; C-220 de 1996, M.P Carlos Gaviria Díaz, y C-583 de 1996, M.P. Vladimiro Naranjo Mesa.

${ }^{20}$ Sentencia C-740 de 1999.

${ }^{21}$ Sentencia C-537 de 1995.

${ }^{22}$ Sentencias C-413 de 1996 y C-538 de 2002.

${ }^{23}$ Sentencia C-504 de 2002.

${ }^{24}$ Según la sentencia C-992 de 2004, el Congreso debe establecer, como mínimo, el "hecho gravable o hecho generador" del tributo.
} 
territorios la tarea de desarrollar los demás elementos ${ }^{25}$.

La Sentencia C-121 de $2006^{[26]}$ resumió la "evolución" de la jurisprudencia sobre el tema hasta entonces: en los primeros años de vigencia de la Constitución, la Corte adhirió a reserva plena de ley ${ }^{27}$, pero luego reconoció la autonomía territorial para dictar o suprimir impuestos de carácter local autorizados en forma genérica por la ley, y para administrar sus tributos propios ${ }^{28}$. Más adelante la Corte reconoció la facultad constitucional de las entidades territoriales para fijar elementos de tributos creados por $\operatorname{ley}^{29}$, y luego fue más allá al sentenciar que, tratándose de tributos territoriales, la competencia del Congreso está compartida con las asambleas o concejos, al punto de afirmar que las facultades del legislador están limitadas a dictar los elementos básicos de los tributos territoriales ${ }^{30}$. Finalmente, la Corte moderó su jurisprudencia, ya que, si bien reiteró que el Congreso no podía vaciar la facultad tributaria de los territorios, podía señalarles "ciertas pautas, orientaciones y regulaciones o limitaciones generales" 31 (Sentencia C-121, 2006).

Como se puede concluir fácilmente de lo expuesto, la jurisprudencia de la Corte en materia de potestad tributaria ha sido cambiante: ha sentenciado desde la posibilidad legal de que el Congreso agote los elementos del tributo, hasta la prohibición a dicha corporación de vaciar las facultades tributarias de los territorios, pasando por una competencia compartida con diversos matices.

La Comisión de Expertos para la Equidad y Competitividad Tributaria ${ }^{32}$, en su informe final, afirma que "[...] los departamentos y municipios no tienen facultad para establecer impuestos. De acuerdo con la Constitución, esa facultad solamente la tiene el Congreso de la República delegando [sic] una parte de su reglamentación a las Asambleas Departamentales y Concejos Municipales" (Bonilla, y otros, 2015, pág. 125). Describe la enorme dispersión de tributos, tarifas y reglamentos, al tiempo que muestra la cada vez más baja participación de los tributos locales en los ingresos agregados de los territorios, que hoy representan el 2,9\% del PIB nacional. Y propone que “[...] conforme a [sic] lo dispuesto por los artículos 150-12 y 338, la ley debe definir los elementos mínimos del impuesto: hecho generador, base, tarifa y sujetos" (ibídem, pág. 173).

Hay quienes opinan que solo es posible la autonomía si existe potestad legislativa, que en Colombia les ha sido "negada por completo [...] a las entidades territoriales, en nombre de la unidad legislativa" (Girón Reguera \& Estupiñán Achury, 2005, pág. 78). Ochoa Maldonado (2011) afirma que la tendencia a robustecer las competencias fiscales de las EE. TT. es armónico con el ideario del Estado Social de Derecho y profundiza el esquema democrático y participativo constitucional.

\footnotetext{
${ }^{25}$ Sentencia C-987 de 1999, reiterada por la sentencia C-227 de 2002.

${ }^{26}$ Transcrita en la Sentencia C-035 de 1999.

${ }^{27}$ Sentencias C-04 de 1993 y C- 467 de 1993, entre otras.

${ }^{28}$ Sentencia C-506 de 1995, entre otras.

${ }^{29}$ Sentencia C-537 de 1995, entre otras.

${ }^{30}$ Sentencias C-1097 de 2001 y C-227 de 2002.

${ }^{31}$ Sentencia C-538 de 2002.

${ }^{32}$ Esta Comisión fue creada según lo dispuesto en el artículo 44 de la Ley 1739 de 2014.
} 
No compartimos esta posición. La democracia y la participación tienen múltiples manifestaciones, pero la potestad tributaria no es necesariamente una de ellas: una adecuada ponderación de los principios de la C.P. lleva a concluir que, además de la concepción unitaria de la República, los principios de justicia y equidad deben prevalecer al determinar los alcances de las atribuciones tributarias de las regiones. Las atribuciones tributarias que la Constitución otorga a los departamentos y a los municipios deben ser vistas como un instrumento y no como un fin. Las finanzas territoriales y la descentralización pueden fortalecerse con otros instrumentos, en particular con las transferencias fiscales: el situado fiscal, la participación de los municipios en los ingresos corrientes de la Nación y la participación de los departamentos y de los municipios en las regalías (Sánchez Torres, 2003) $3^{33}$.

En concordancia con lo dicho, permitir -e incluso sentenciar- que las facultades del Congreso se limiten a la definición de los aspectos básicos del tributo, valga decir, sujeto activo y hecho generador, y dejar al arbitrio de los territorios elementos como el sujeto pasivo, la base gravable y la tarifa, como lo dictan las sentencias C-413 de 1996 y C-891 de 2012, rompe de alguna manera la estructura unitaria del país en materia fiscal toda vez que abre la puerta para que los tributos resulten notablemente distintos entre dos municipios o dos departamentos. Esta circunstancia, que en modo alguno considera inconveniente la Corte ${ }^{34}$, da espacio para que los contribuyentes busquen arbitrar rentas, es decir, planificar sus negocios para obtener beneficios de esas asimetrías, lo que conduce a que las EE. TT. compitan entre ellas en materia fiscal, algo que, si bien es entendible entre Estados e incluso entre Federaciones al interior de un mismo Estado, no es razonable que se dé al interior de país que se proclama unitario.

Por otra parte, la notable diversidad de tributos, tarifas y formalidades en los departamentos, distritos y municipios del país conduce a ineficiencia tributaria, valga precisar, a altos costos en su administración, y a altos riesgos y costos de cumplimiento para el contribuyente ${ }^{35}$. En efecto, un contribuyente que resulta ser sujeto pasivo en varios territorios, se ve abocado, por la heterogeneidad sustancial y formal ${ }^{36}$ de los tributos

\footnotetext{
${ }^{33}$ Sobre descentralización y transferencias fiscales, ver Finot (2005).

34 “[...] algunos manifestarán que en el plano municipal, a tiempo que unos concejos podrían establecer una estampilla con tarifa moderada o baja, otros por su parte ejercerían sus facultades estipulando una estampilla con tarifa más alta frente a iguales hechos gravables, generándose así tarifas diferenciales contrarias al principio de equidad tributaria. [...]. Sin embargo, en presencia de dichas sindicaciones se impone observar que, tratándose de tributos territoriales la igualdad debe entenderse dentro de cada jurisdicción y no con referencia al plano nacional" (Sentencia C-1097 de 2001).

${ }^{35}$ Sobre la eficiencia tributaria, la jurisprudencia ha considerado que "su objetivo es lograr que el tributo se recaude con el menor costo posible para el Estado y para el contribuyente. En ese contexto, el citado principio resulta ser 'un recurso técnico del sistema tributario dirigido a lograr el mayor recaudo de tributos con un menor costo de operación; pero de otro lado, se valora como principio tributario que guía al legislador para conseguir que la imposición acarree el menor costo social para el contribuyente en el cumplimiento de su deber fiscal (gastos para llevar a cabo el pago del tributo)" (Sentencia C-913-11, 2011).

${ }^{36}$ Una disposición que sin duda va en la vía de la eficiencia tributaria, es la armonización de las normas de procedimiento tributario en los territorios con las previstas en el Estatuto Tributario Nacional (artículo 66 de la Ley 383 de 1997, subrogado y ampliado por el artículo 59 de la Ley 788 de 2002).
} 
(producto de la excesiva autonomía fiscal), a cumplir con un sinnúmero de obligaciones igualmente diversas en cada municipio o departamento en que realiza algún hecho generador.

A nuestro juicio, la baja capacidad que tienen la enorme mayoría de administraciones locales para gestionar un sistema tributario complejo, el bajo recaudo que generan muchos de los tributos vigentes y la dudosa legalidad de muchos de estos, llama a que se profundice la reserva de ley. Y no solo es un asunto de conveniencia tributaria, política o económica: la concepción constitucional del país como república unitaria obliga a que exista una razonable uniformidad entre los territorios en materia fiscal. Por lo anterior, concordamos con la propuesta que hace la Comisión, aunque no con la afirmación que, en términos efectivos, niega a rajatabla cualquier potestad tributaria a las EE. TT. Creemos que puede darse cierto margen de maniobra a las asambleas y concejos en la fijación de las tarifas y las exenciones.

En otras palabras, consideramos que la Corte debería revisar su jurisprudencia, y ponderar lo previsto en los artículos 287 y 338 Superiores, con los principios de equidad, eficiencia y progresividad prescritos en el artículo 363, y con el postulado de República unitaria expresado en el artículo 1 de la Carta. La delegación en los territorios de la fijación de las bases gravables de los tributos y el amplio margen que la Corte les da para fijar la tarifa a su arbitrio son competencias que pueden conducir a situaciones inequitativas entre dos sujetos pasivos que, teniendo la misma capacidad económica y bajo situaciones de hecho similares, se vean abocados a una tributación local desigual al interior de la República unitaria -aunque para la Corte ello no sea reprochable- y a que se desaprovechen eficiencias que solo pueden darse si las reglas tributarias entre territorios son más o menos uniformes.

\section{Conclusión}

El constituyente erigió el sistema tributario en diversas disposiciones que versan sobre distintos tópicos y que se encuentran dispersas en varios títulos constitucionales. No tuvo el cuidado de emplear un vocabulario técnico y consistente -e incluso muchas veces los términos son incoherentes-al redactar las disposiciones tributarias.

Por ello, ha obligado a que la ley, y ante todo la jurisprudencia, hayan debido asumir la tarea de armar el rompecabezas tributario y sentar unas bases constitucionales más o menos claras, en la búsqueda de la seguridad jurídica debida en una materia que no solo tiene innegables implicaciones en el desarrollo de la sociedad y su devenir económico, sino también en la aplicación de otros principios y derechos establecidos en la misma Constitución, tales como el orden económico y social justo, la solidaridad y la prosperidad.

Más allá de la dispersión normativa del sistema tributario constitucional, muchas de las normas estructurales de nuestro sistema legal tributario vigente fueron decretadas antes de la promulgación de la Carta vigente. Gracias a ello, la terminología legal se ha mantenido razonablemente consistente con los postulados aceptados por los técnicos tributaristas, y la imprecisión de los términos constitucionales no ha sido un argumento relevante en la generalidad de las demandas de inexequibilidad o nulidad de las normas tributarias. En todo caso -hay que decirlo-, las sentencias de las altas cor- 
tes tampoco han sido dechado de consistencia y precisión en su vocabulario tributario.

Uno de los temas en los que la Constitución no es del todo precisa es el del reparto de la potestad tributaria, y en particular la reserva de ley, cuando faculta, en principio sin distingos jerárquicos, a la ley, las ordenanzas y los acuerdos para fijar tributos y contribuciones (artículo 338 y 287.3). No obstante, en el caso de los departamentos, el art. 300.4 subordina la fijación de "tributos y contribuciones" a la ley, pero el constituyente agregó una fuente adicional a la potestad tributaria de distritos y municipios, toda vez que faculta a los concejos para que voten los tributos locales no solo de acuerdo con la ley, sino también de acuerdo con la Constitución (artículo 313.4).

Cabe preguntarse por qué, si el constituyente quería mantener la reserva de ley en materia tributaria, no dejó tal previsión en forma expresa en el articulado y subordinó la facultad de los territorios a fijar los elementos tributarios de acuerdo con la ley. La duda se acrecienta al leer la exposición de motivos (Gaceta Constitucional 53), en la que se expone la inoperancia de una descentralización sin contar con el privilegio de disponer en forma autónoma de recursos propios.

La Corte ha sido consistente en sentenciar la reserva de ley en la originación de los tributos, con base, esencialmente, en la concepción unitaria de la República. Sin embargo, la Corporación ha dicho que al Congreso no se le puede permitir agotar los elementos del tributo territorial, sino que se debe asegurar que sean las asambleas y los concejos los que, en virtud de la autonomía fiscal que les otorga la Constitución, los decreten a partir de la génesis básica que de ellos haga la ley. Dicho en otras palabras, una vez el Congreso ha decretado los elementos básicos del tribu- to territorial, las corporaciones territoriales cuentan con la facultad inalienable envestida por la C.P. para fijar los demás elementos de sus tributos.

No le faltan argumentos a la posición de quienes proponen que las facultades tributarias de los territorios se deben definir en una ley orgánica de asignación de competencias, al tenor del artículo 151 de la Carta. Del tema no se ha ocupado el Congreso y, en todo caso, consideramos conveniente que, en una República unitaria, los elementos del tributo se fijen por la ley, salvo un margen menor en tarifas o exenciones.

Creemos que una adecuada ponderación de las normas constitucionales puede permitirle a la Corte replantear su línea jurisprudencial, de forma tal que se enfoque, más que en la defensa de los artículos que otorgan autonomía tributaria a los territorios -que dictan postulados de corte político/administrativo-, en los principios rectores del sistema tributario previstos en el artículo 363 de la C.P., ya que solo así se garantiza que se hagan efectivos derechos fundamentales como el previsto en el artículo 13 (igualdad), y se dé cumplimiento a la obligación ciudadana de contribuir, pero dentro del "concepto" de justicia (artículo 95.9). En este orden de ideas, debería la Corte revisar su posición en matera de potestad tributaria, y asegurar la reserva de ley, no solo en los elementos básicos del tributo, sino también en la base gravable y el rango tarifario. La potestad territorial debe circunscribirse a la adopción o no del tributo, a disponer de un margen para fijar la tarifa -como sucede hoy en día en impuestos como el de Industria y Comercio, aunque con rangos menos amplios-y a decretar las exenciones que considere procedentes. 


\section{BIBLIOGRAFÍA Y REFERENCIAS}

Asamblea Nacional Constituyente (1991). Gaceta Constitucional $n .^{\circ} 53$.

Bonilla, R.; Córdoba, R.; Lewin, A.; Morales, O. D.; Montoya, S.; Perry, G. y otros (2015). Informe final de la Comisión de Expertos para la Equidad y la Competitividad Tributaria, presentado al ministro de Hacienda y Crédito Público.

CIAT; GIZ; BID (2015). Modelo de Código Tributario del CIAT: Un enfoque basado en la experiencia iberoamericana. Panamá: CIAT.

Corte Constitucional. Sentencia C-913-11, Expediente D-8572. M.P. Gabriel Eduardo Mendoza Martelo. 6 de dic. de 2011 .

Corte Constitucional. Sentencia C-134, Expediente D-7371. M.P. Mauricio González Cuervo. 25 de feb. de 2009.

Corte Constitucional. Sentencia C-891, Expediente D-9063. M.P. Joge Ignacio Pretelt Chaljub. 31 de oct. de 2012.

Corte Constitucional. Sentencia C-227, Expediente D-3699. M.P. Jaime Córdoba Triviño. 2 de abr. de 2002.

Corte Constitucional. Sentencia C-121, Expediente D-5927. M.P. Marco Gerardo Monroy Cabra. 22 de feb. de 2006.

Domingues, J. M., \& Checa González, C. (2013). “Concepto de tributo: una perspectiva comparada BrasilEspaña”, en Revista Direito GV , 9 (2), 573-614.

Finot, I. (2005). “Descentralización, transferencias territoriales y desarrollo local”, en Revista de la CEPAL (86), $29-46$.

Girón Reguera, E. \& Estupiñán Achury, L. (2005). "Una aproximación a la jurisprudencia constitucional colombiana en materia territorial”, en Diálogos de saberes: investigaciones y ciencias sociales, 57-80.

Ochoa Maldonado, O. A. (2011). "Reflexiones en torno a la autonomía tributaria de las entidades territoriales en el contexto del Estado Social de Derecho", en Revista Jurídica Piélagus , 10 (10), 78-89.

Pecho-Trigueros, M. E. (2010). Tributación y Administración Tributaria en los Países Miembros del CIAT. CIAT.

Rodríguez Gutiérrez, C. E. (2005). "Poder tributario y entidades territoriales. El caso colombiano en la Constitución de 1991”, en Estudios Socio-Jurídicos , 7 (2), 173-190.

Real Academia Española (2014). Diccionario de la lengua española (23a ed.). Madrid.

Insignares Gómez, R. \& Sánchez Peña, M. C. (2010). "Poder tributario: organización y estructura en el Estado colombiano", en J. R. Piza Rodríguez (ed.). Curso de derecho tributario, procedimiento y régimen sancionatorio (págs. 67-112). Bogotá: Universidad Externado de Colombia.

Sánchez Torres, C. A. (2003). "El concepto constitucional de autonomía fiscal y sus alcances legales y jurisprudenciales en Colombia a partir de la Constitución Política de 1991”, en Estudios Socio-Jurídicos , 5 (1), $172-210$.

Upegui Mejía, J. C. (2009). "Principios constitucionales del derecho tributario en Colombia y México", en Revista de Derecho Fiscal (5). 